\title{
Revealing Lattice Expansion of Small-Pore Zeolite Catalysts during the Methanol-to-Olefins Process Using Combined Operando X-ray Diffraction and UV-vis Spectroscopy
}

\author{
Joris Goetze, ${ }^{\dagger}$ Irina Yarulina, ${ }^{\ddagger}, \S$ Jorge Gascon, ${ }^{\ddagger, \S}$ Freek Kapteijn, ${ }^{\ddagger \odot}$ and Bert M. Weckhuysen ${ }^{*}, \dagger \odot$
}

${ }^{\dagger}$ Inorganic Chemistry and Catalysis, Debye Institute for Nanomaterials Science, Utrecht University, Universiteitsweg 99,3584 CG

Utrecht, The Netherlands

*Catalysis Engineering, Chemical Engineering Department, Delft University of Technology, Van der Maasweg 9, 2629 HZ Delft, The Netherlands

${ }^{\S}$ King Abdullah University of Science and Technology, KAUST Catalysis Center, Advanced Catalytic Materials, Thuwal 23955, Saudi Arabia

\section{Supporting Information}

ABSTRACT: In small-pore zeolite catalysts, where the size of the pores is limited by eight-ring windows, aromatic hydrocarbon pool molecules that are formed inside the zeolite during the Methanol-to-Olefins (MTO) process cannot exit the pores and are retained inside the catalyst. Hydrocarbon species whose size is comparable to the size of the zeolite cage can cause the zeolite lattice to expand during the MTO process. In this work, the formation of retained hydrocarbon pool species during MTO at a reaction temperature of $400{ }^{\circ} \mathrm{C}$ was followed using operando UV-vis spectroscopy. During the same experiment, using operando X-ray Diffraction (XRD), the expansion of the zeolite framework was assessed,

Species causing lattice expansion during MTO: $\mathrm{CHA}$

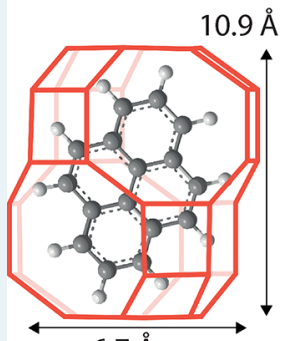

$6.7 \AA$ DDR

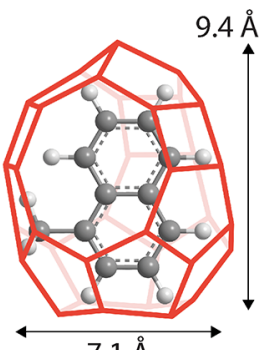

$7.1 \AA$
LEV

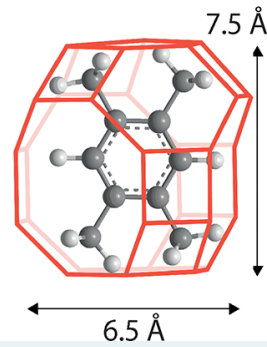
and the activity of the catalyst was measured using online gas chromatography (GC). Three different small-pore zeolite frameworks, i.e., CHA, DDR, and LEV, were compared. It was shown using operando XRD that the formation of retained aromatic species causes the zeolite lattice of all three frameworks to expand. Because of the differences in the zeolite framework dimensions, the nature of the retained hydrocarbons as measured by operando UV-vis spectroscopy is different for each of the three zeolite frameworks. Consequently, the magnitude and direction of the zeolite lattice expansion as measured by operando XRD also depends on the specific combination of the hydrocarbon species and the zeolite framework. The catalyst with the CHA framework, i.e., H-SSZ-13, showed the biggest expansion: 0.9\% in the direction along the $c$-axis of the zeolite lattice. For all three zeolite frameworks, based on the combination of operando XRD and operando UV-vis spectroscopy, the hydrocarbon species that are likely to cause the expansion of the zeolite cages are presented; methylated naphthalene and pyrene in CHA, 1-methylnaphthalene and phenalene in DDR, and methylated benzene and naphthalene in LEV. Filling of the zeolite cages and, as a consequence, the zeolite lattice expansion causes the deactivation of these small-pore zeolite catalysts during the MTO process.

KEYWORDS: Methanol-to-Olefins, zeolites, operando, UV-vis spectroscopy, X-ray diffraction, Rietveld refinement, lattice expansion, deactivation

\section{INTRODUCTION}

In the Methanol-to-Olefins (MTH) process over zeolite catalysts, methanol reacts with a hydrocarbon pool inside the zeolite pores. This hydrocarbon pool consists of aromatic and olefinic hydrocarbons that can be neutral or charged by the zeolite framework, depending on which step of the reaction mechanism is taking place. These hydrocarbon pool species are methylated by the methanol feed and subsequently dealkylated to form the main MTO products, i.e., lower olefins. ${ }^{1}$ Depending on their size, these hydrocarbon pool species can also leave the zeolite as products themselves. For example, small aromatics, such as methylated benzenes, can leave medium-pore zeolite frameworks, such as MFI, which have ten-ring pores with a pore diameter of ca. 5 Å. However, when small aromatic molecules are formed in small-pore zeolite frameworks, such as CHA, with eight-ring pores with a diameter $<4 \AA$, these molecules cannot exit the pores and are retained inside the zeolite pores. For this reason, during the MTO process over zeolite catalysts, hydrocarbons accumulate in the zeolites with increasing time-on-stream. These species

Received: December 2, 2017

Revised: January 23, 2018

Published: February 6, 2018 
can be active hydrocarbon pool species that are being methylated by the methanol feed and subsequently dealkylated to form MTO products, but they can also grow into species that are not active in producing olefins anymore. These species inside the zeolite pores deactivate the catalyst by preventing access to the active species. ${ }^{2}$ In addition, hydrocarbons can also be deposited on the outer surface of the catalyst, where they can grow into large polyaromatic structures that also block the zeolite pores. Inactive hydrocarbons inside or outside the zeolite pores that deactivate the catalyst by preventing methanol from reaching the active sites or by preventing products from leaving the zeolite pores are referred to as coke, and coke formation is the main reason for deactivation of MTO catalysts. Following the evolution of the hydrocarbon pool and the retained species is important for understanding the MTO process and deactivation of the catalyst. Accumulation of hydrocarbon species inside the zeolite catalyst can be investigated using operando spectroscopic techniques, such as nuclear magnetic resonance (NMR), ${ }^{3}$ Raman, ${ }^{4}$ infrared, ${ }^{5,6}$ and UV-vis spectroscopy. ${ }^{6-12}$

Formation of hydrocarbon species inside the zeolite pores can cause the zeolite framework to expand. Zeolites are crystalline microporous materials, and when the zeolite framework expands because of the formation of hydrocarbon species that build up inside the cages, the lattice parameters of the crystalline zeolite change. This change in lattice parameters can be characterized using X-ray diffraction (XRD). It has been shown before using XRD that the buildup of hydrocarbons inside the pores of the zeolite can cause the zeolite pore network to expand. This phenomenon has been studied extensively by Wragg and co-workers. ${ }^{13-18}$ Primarily, lattice expansion caused by hydrocarbon formation in SAPO-34 catalysts (CHA framework) has been studied using a combination of ex situ laboratory XRD as well as in situ synchrotron-based XRD. ${ }^{13-18}$ In addition to SAPO-34, changes in lattice parameters of other small-pore SAPO-materials, such as SAPO-18 (AEI framework), ${ }^{14}$ as well as medium-pore zeolite materials including ZSM-22 (TON framework) ${ }^{19}$ and ZSM-5 (MFI framework), have been investigated. ${ }^{20}$ Wragg et al. observed that in SAPO-34 zeotype catalyst with CHA framework topology, bulky hydrocarbon species cause an expansion of the zeolite cages in the direction of the $c$-axis of ca. $2-3 \%$ during the conversion of methanol to olefins at a reaction temperature of $440-500{ }^{\circ} \mathrm{C}$, while the $a$ - and $b$-axes showed almost no change. ${ }^{13,16}$ In a recent paper by Svelle et al., the deactivation of ZSM-5 catalysts during the Methanol-toGasoline (MTG) process was studied using a combination of XRD and other methods to characterize coke formation and deactivation, such as thermogravimetric analysis (TGA) and acidity characterization methods. Different types of ZSM-5 catalysts showed different expansion/contraction behavior, but using this combination of techniques, the authors were able to define a descriptor for the degree of deactivation of ZSM-5 based on the difference in length of the zeolite lattice $a$ - and $b$ axis. $^{21}$ This shows that the amount of lattice expansion or contraction caused by coke formation is dependent on the specific zeolite framework that is used as catalyst. In this study, the lattice expansion of three small-pore zeolite frameworks, i.e., CHA, DDR, and LEV, during the conversion of methanol is studied and related to the hydrocarbon species that are retained during MTO.

In our previous work, we investigated the nature and evolution of the hydrocarbon pool during the MTO process for the same three small-pore zeolites (CHA, DDR, and LEV), using UV-vis spectroscopy. ${ }^{10}$ We showed that small differences in size and shape of the cages of these small-pore zeolites results in a different nature and evolution of the hydrocarbon pool during MTO, and that this has implications on activity and deactivation of the three catalysts. Furthermore, by combining operando UV-vis spectroscopy with other characterization methods, such as GC/MS of extracted coke species and thermogravimetric analysis (TGA), it was shown that the main reason for deactivation of these small-pore zeolites is filling of the pores with hydrocarbon deposits, rather than the formation of coke on the external surface of the zeolite. In this work, we combine operando UV-vis spectroscopy to study the formation of hydrocarbon species during the MTO process with operando XRD to follow the expansion of the zeolite lattice. The operando XRD experiments are performed in a unique laboratory diffractometer setup equipped with a Mo Xray source in order to obtain enough signal, without the need for synchrotron radiation. The setup combines operando XRD with operando UV-vis spectroscopy. Activity data is obtained at the same time using online gas chromatography (GC). Three small-pore zeolite frameworks, i.e., CHA, DDR, and LEV, are compared. In this way, a link can be made between the accumulation of hydrocarbon pool species, expansion of the zeolite lattice, and MTO activity.

\section{EXPERIMENTAL SECTION}

2.1. Materials Synthesis and Characterization. Synthesis of the zeolite catalysts with CHA (SSZ-13), DDR (Sigma-1), and LEV (Nu-3) topology was performed by seedassisted growth using crystals with the corresponding topology as seeds $(0.1 \mathrm{wt} \%)$ in order to reduce synthesis time. Synthesis of the seeds was based on existing recipes with some modifications from the open literature. ${ }^{22-25}$ Ludox HS-40 was used as silica source and $\mathrm{NaAlO}_{2}$ was used as alumina source. The crystals that were synthesized by seed-assisted growth were calcined for $10 \mathrm{~h}$ at $650{ }^{\circ} \mathrm{C}$, and subsequently converted into their protonic form by a triple ion-exchange in aqueous $\mathrm{NH}_{4} \mathrm{NO}_{3}$ solution $\left(1 \mathrm{M}, 80^{\circ} \mathrm{C}, 2 \mathrm{~h}, 100 \mathrm{~mL}\right.$ per gram of zeolite), followed by a calcination at $550{ }^{\circ} \mathrm{C}$. The zeolite samples used in this work are the same as studied in our previous work, and a more detailed description of the synthesis procedure can be found in the Supporting Information. ${ }^{10}$

The physical properties of the zeolites were characterized using SEM and ICP-OES, whereas the acidic properties were analyzed using $\mathrm{NH}_{3}-\mathrm{TPD}$, and $\mathrm{CO}$ adsorption followed by IR spectroscopy. The experimental details can be found in the Supporting Information. ${ }^{10}$

2.2. Combined Operando X-ray Diffraction and UVvis Spectroscopy. Using a combined operando XRD and UV-vis spectroscopy setup, the nature and evolution of the hydrocarbon pool was measured using operando UV-vis spectroscopy, and the resulting zeolite lattice expansion was measured using operando XRD. The experimental setup is built inside the case of a Bruker D8 Discover diffractometer, and a previous version of this experimental setup was described in an earlier paper from the Inorganic Chemistry and Catalysis group of Utrecht University. ${ }^{26}$ In that work, the operando XRD measurements were used in order to identify different crystalline phases during different stages of a catalytic reaction. However, in the current work, the setup was used to follow the change in crystal lattice parameters of a single crystalline phase during the reaction. A schematic of the setup is shown in Figure 


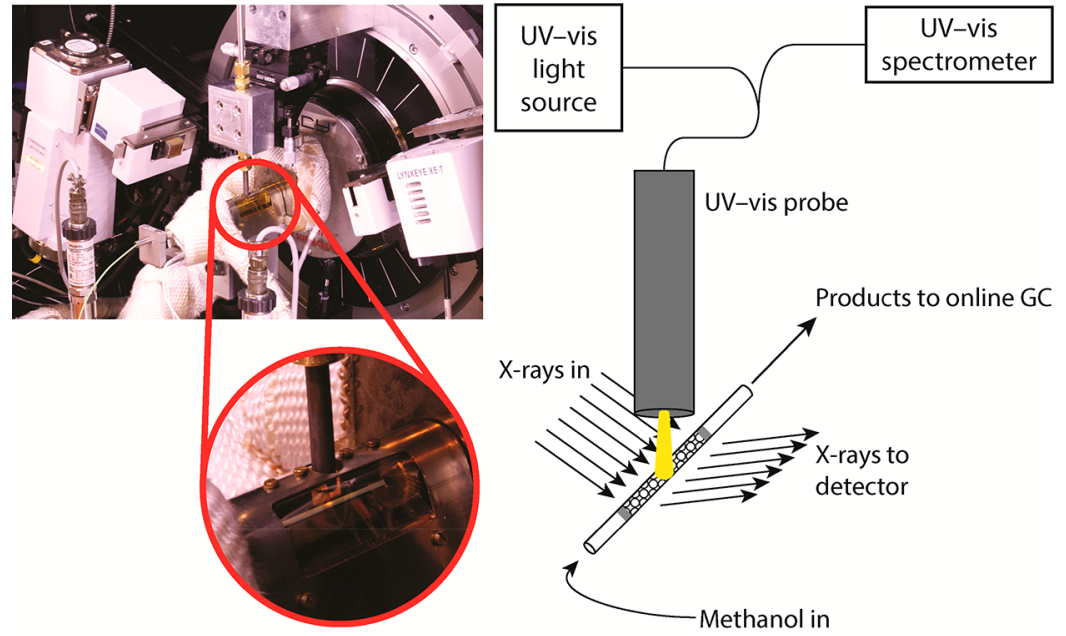

Figure 1. Schematic of the combined operando X-ray diffraction and UV-vis setup showing the X-ray diffractometer with the mounted capillary; in the middle of the capillary, the spot of the UV-vis light source can be seen (see inset).

1. $\mathrm{MoK}_{\alpha}$ radiation with a wavelength of $0.709 \AA$ was used. The $\mathrm{X}$-rays were focused on a quartz capillary (OD $1 \mathrm{~mm}$, wall thickness $0.01 \mathrm{~mm}$ ) using a Göbel mirror. In this way, diffraction patterns of a catalyst bed inside the capillary with a bed length of ca. $20 \mathrm{~mm}$ were recorded. Photons were detected using an energy dispersive Lynxeye XE-T detector, making it possible to filter $\mathrm{K}_{\beta}$ radiation from the signal.

UV-vis spectra were recorded using a high-temperature UV-vis fiber optics probe, connected to an AvaSpec 2048L spectrometer and an AvaLight-DH-S-BAL light source. The spectra were measured in the middle of the catalyst bed, in a spot with a diameter of ca. $1 \mathrm{~mm}$. This means that whereas the operando XRD patterns are an average over the complete catalyst bed, the operando UV-vis spectra are taken from a much smaller amount of catalyst, in the middle of the catalyst bed.

The catalyst bed was heated using an infrared furnace, and the temperature was controlled using a thermocouple that was inserted into the capillary and into the catalyst bed. Gas flows were controlled using multiple mass flow controllers that are installed inside the diffractometer cabinet. Both low pressure and high pressure gas can be used, making the setup usable not only for the MTO process but also for other processes such as, e.g., Fischer-Tropsch synthesis (FTS) ${ }^{26}$ or Fischer-Tropschto-olefins (FTO).

Products were detected online using a Thermo Scientific TRACE 1300 gas chromatograph (GC) equipped with multiple columns and multiple FID and TCD detectors in order to detect MTO products as well as methanol and dimethyl ether.

In a typical experiment, $8 \mathrm{mg}$ of catalyst with aggregate size between 150 and $212 \mu \mathrm{m}$ is loaded in the capillary, resulting in a bed length of ca. $20 \mathrm{~mm}$. The capillary is placed into the setup and heated to $450{ }^{\circ} \mathrm{C}$ in $\mathrm{O}_{2}$ with a rate of $5{ }^{\circ} \mathrm{C} / \mathrm{min}$. The catalyst is kept at $450{ }^{\circ} \mathrm{C}$ under $\mathrm{O}_{2}$ flow in order to burn off any possible hydrocarbon contamination present in the zeolite before starting the reaction. After $1 \mathrm{~h}$, the temperature is lowered to $400{ }^{\circ} \mathrm{C}$ with a rate of $5{ }^{\circ} \mathrm{C} / \mathrm{min}$, and the flow is switched to He. Before methanol is introduced into the setup, an XRD pattern is recorded. Subsequently, methanol is introduced into the capillary at a WHSV of $3 \mathrm{~g}_{\mathrm{MeOH}} \mathrm{g}_{\text {cat. }} \mathrm{h}^{-1}$ by flowing the He through a saturator that is kept at ca. $40{ }^{\circ} \mathrm{C}$, resulting in a $\mathrm{MeOH}$ concentration of ca. 34\%. During the reaction, activity data is obtained using online GC, and operando XRD patterns and operando UV-vis spectra are recorded. After deactivation of the catalyst, the methanol saturator is closed and a final XRD pattern is recorded.

In order to determine the zeolite lattice parameters from XRD patterns, Rietveld refinements were performed on full powder patterns using TOPAS academic V5, starting with framework positions from the IZA-SC Database of Zeolite Structures. $^{27}$ The background was fitted with a 5-term Chebyshev function, as well as a $1 / \mathrm{X}$ background function to account for air scattering at low angles. The lattice parameters for the hexagonal unit cell and symmetry independent framework atom positions were refined. The peak shape was described using a pseudo-Voigt function, and the crystallite size broadening was described using a Lorentzian function. To account for the coke in the zeolite pores after the MTO process, carbon atoms were placed inside the zeolite cage, and their occupancies were refined. In order to assess whether observed lattice expansions were statistically significant, a paired $t$-test was performed. Using this statistical method, the means and standard deviations $(n=3)$ of the lattice parameters of the zeolite materials before reaction were compared to those after performing the MTO reaction. The $p$-value resulting from this $t$-test represents the probability that the changes in lattice parameters during the MTO process are not statistically significant. In our work, changes in lattice parameters with a $p$-value $>0.05$ were considered as not statistically significant.

\section{RESULTS}

3.1. Comparison of Zeolite Frameworks for the MTO Process: Previous Results. In our previous work, the three small-pore zeolite frameworks, i.e., CHA, DDR, and LEV, were compared during the MTO process using operando UV-vis spectroscopy and online gas chromatography (GC), and a more detailed discussion of the comparison of the three zeolite frameworks during the MTO process can be found there. ${ }^{10}$ In this section, a summary of the results that are important for this work is given. An overview of the physical properties of the three zeolite materials is presented in Table 1. It can be seen that properties, such as crystallite size, acid-site density, and acid strength, are comparable for the three zeolite frameworks, meaning that the comparison of the materials is mainly based on the differences in framework structure. The main differences 
Table 1. Physical Properties of the Zeolite Materials under Study ${ }^{10}$

\begin{tabular}{|c|c|c|c|}
\hline & CHA & DDR & LEV \\
\hline cage dimensions $\left(\AA^{2}\right)^{27}$ & $6.7 \times 10.9$ & $7.1 \times 9.4$ & $6.5 \times 7.5$ \\
\hline window dimensions $\left(\AA^{2}\right)^{27}$ & $3.8 \times 3.8$ & $3.6 \times 4.4$ & $3.8 \times 4.4$ \\
\hline crystal shape & cubic & platelet & cuboid \\
\hline pore structure $(2-\mathrm{D} / 3-\mathrm{D})$ & $3-\mathrm{D}$ & 2-D & $2-\mathrm{D}$ \\
\hline $\begin{array}{l}\mathrm{Si} / \mathrm{Al} \text { ratio (measured with } \mathrm{ICP} / \\
\text { theoretical) }\end{array}$ & $59 / 60$ & $50 / 30$ & n.d./30 \\
\hline $\begin{array}{l}\text { amt of acid sites } \\
\quad(\mathrm{mmol} \mathrm{NH} / \mathrm{g} \text { cat. })\end{array}$ & 0.29 & 0.34 & 0.80 \\
\hline acid sites per cage & 0.20 & 0.39 & 0.41 \\
\hline $\mathrm{NH}_{3}-\mathrm{TPD}$ peak $1\left({ }^{\circ} \mathrm{C}\right)$ & 167 & 167 & 167 \\
\hline $\mathrm{NH}_{3}$-TPD peak $2\left({ }^{\circ} \mathrm{C}\right)$ & 435 & 405 & 425 \\
\hline $\begin{array}{l}\text { IR shift of Brønsted OH-peak upon } \\
\text { CO-adsorption }\left(\mathrm{cm}^{-1}\right)\end{array}$ & $315 \mathrm{~cm}^{-1}$ & $316 \mathrm{~cm}^{-1}$ & $307 \mathrm{~cm}^{-1}$ \\
\hline
\end{tabular}

in framework properties are the size and shape of the zeolite cages, as well as the dimensionality of pore structure (3-D for CHA, and 2-D for DDR and LEV).

Using operando UV-vis spectroscopy during the MTO process, combined with GC/MS analysis of the retained hydrocarbons after the MTO process, it was shown that the differences in cage dimensions and pore structure between CHA, DDR, and LEV result in a different nature of retained hydrocarbons during MTO. In the CHA cage, the hydrocarbon species inside the zeolite cages are various methylated benzenes and naphthalenes, whereas in the smaller and less symmetric DDR cage, in addition to methylated benzenes, mainly one kind of methylated naphthalene, i.e., 1-methylnaphthalene, is present. In the LEV cage, the smallest of the three cages, naphthalene was found in the cages, but methylated naphthalenes are too large to fit inside. Furthermore, it was shown that the reaction temperature has an important influence on catalyst lifetime of the DDR and LEV framework, because some species that deactivate the catalyst by blocking the zeolite pores at lower reaction temperature (i.e., $350{ }^{\circ} \mathrm{C}$ ) are methylated and dealkylated to form olefins at reaction temperatures of 400 and $450{ }^{\circ} \mathrm{C}$. At reaction temperatures of $400{ }^{\circ} \mathrm{C}$ and higher, filling of all zeolite cages with hydrocarbon species is the reason for deactivation of the catalyst. ${ }^{10}$

In UV-vis spectroscopy, the difference in nature of the retained hydrocarbons inside the zeolite pores could also be observed. For CHA, in which the largest variety of hydrocarbon species is present during MTO, the UV-vis spectra generally show broad, convoluted features and the spectrum is dominated by a large band around $25000 \mathrm{~cm}^{-1}$, caused by charged alkylated benzenes and naphthalenes. For DDR, a smaller variety of hydrocarbon species result in sharper bands in UV-vis. The large absorption band around $25000 \mathrm{~cm}^{-1}$ is also present, and it has a sharp shoulder at $24800 \mathrm{~cm}^{-1}$, caused by 1-methylnaphthalene. In the small LEV cage, the band around $25000 \mathrm{~cm}^{-1}$ is much smaller, because the methylated benzenes and naphthalenes do not fit inside the cage. ${ }^{10}$

3.2. Combined Operando UV-vis Spectroscopy and X-ray Diffraction. In our combined operando UV-vis spectroscopy and X-ray diffraction setup, UV-vis spectra were taken from a spot in the middle of the catalyst bed, whereas XRD patterns were taken over the complete bed during the conversion of methanol. In Figures 2-4, an overview of the data obtained for the different zeolite frameworks on the
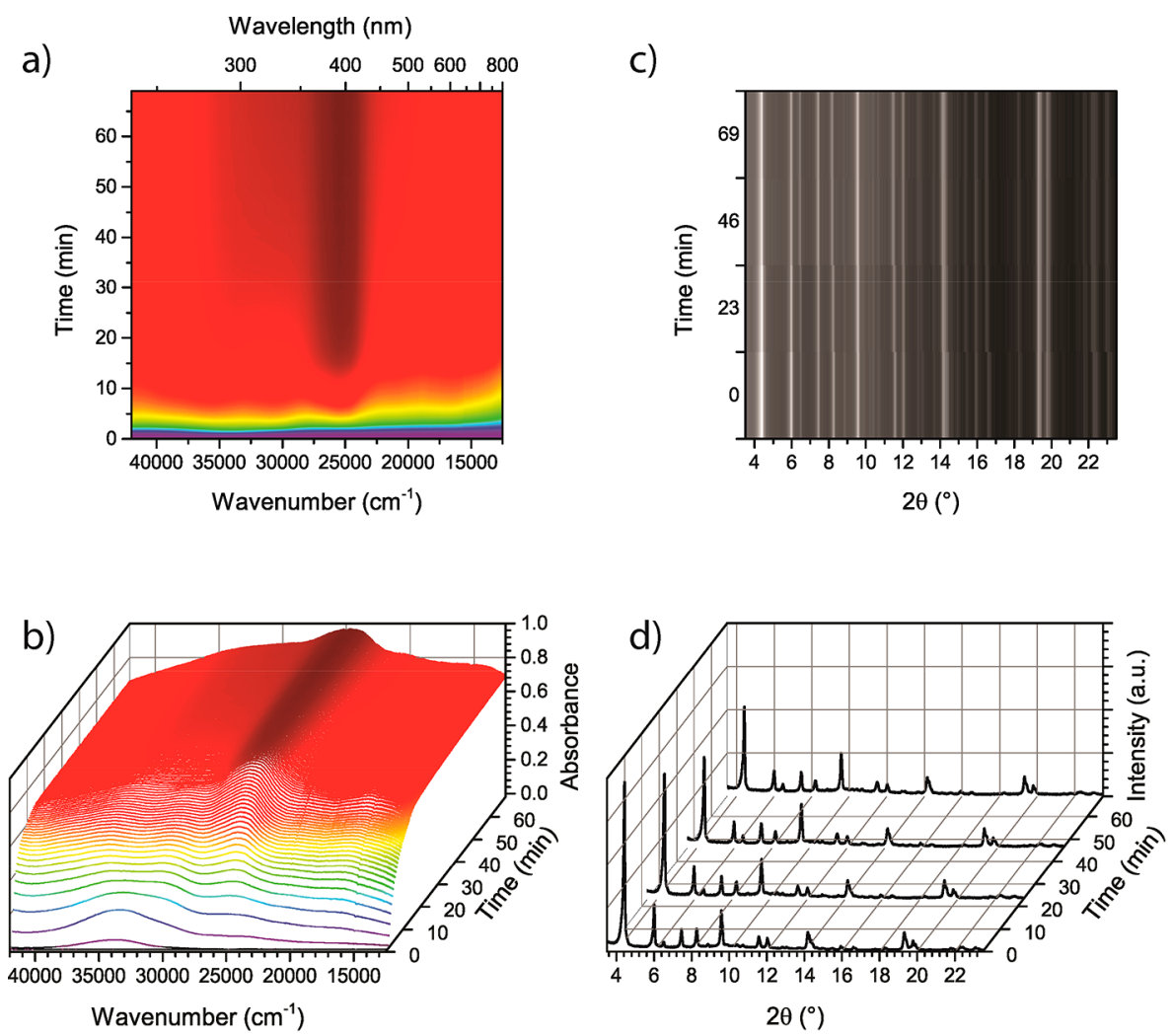

e)
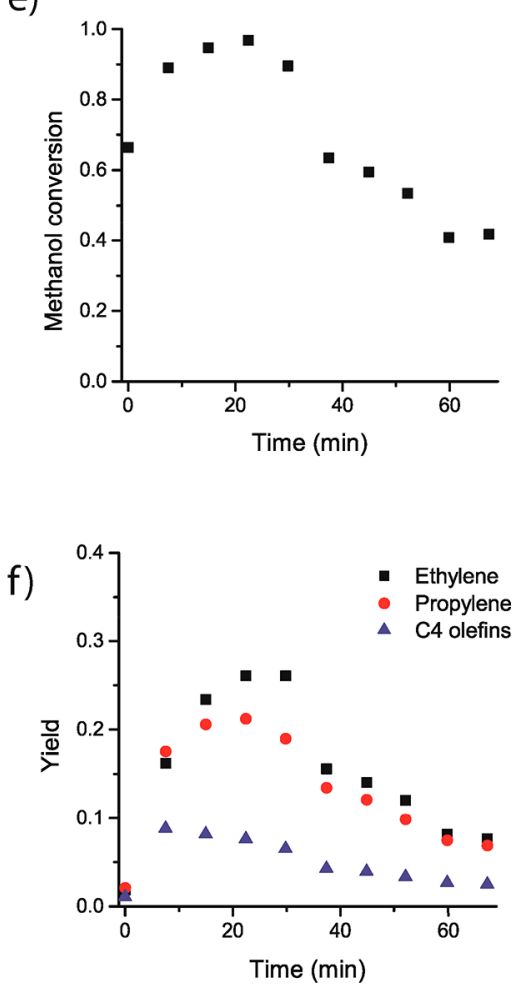

Figure 2. Overview of data obtained from the combined operando XRD and UV-vis setup for the CHA catalyst: (a) contour and (b) waterfall plot of operando UV-vis spectra during the conversion of methanol; (c) contour and (d) waterfall plot of operando X-ray diffraction patterns during the conversion of methanol; (e) methanol conversion and (f) lower olefin yield measured using online GC. 
combined operando XRD and UV-vis setup is presented. In (a) and (b), operando UV-vis spectra are shown as a contour plot and as a waterfall plot, respectively; (c) and (d) show contour and waterfall plots of the operando X-ray diffraction patterns; and in (e) and (f) the activity data is shown. In principle, all data is obtained in a single experiment. However, due to the long time interval between subsequent GC injections compared to the time scale of the MTO process before deactivation, the activity data was built from three identical experimental runs; i.e., the first GC injection was timed at $t=0$ min, $\mathrm{t}=7.5 \mathrm{~min}$, and $t=15 \mathrm{~min}$, respectively, and the three runs were combined in order to show activity data with a higher time resolution. Due to limitations of the experimental setup, the methanol concentration could not be lower than ca. 34\%, and the space velocity could not be lowered further than a WHSV of $3 \mathrm{~g}_{\mathrm{MeOH}} \mathrm{g}_{\text {cat. }}{ }^{-1} \mathrm{~h}^{-1}$.

For CHA, the activity data shows a period of methanol conversion $>90 \%$, and during this time, the main products are lower olefins. After that, the methanol conversion drops to below 50\%, and olefin yield also drops. At that moment, the remaining activity is mainly toward the formation of dimethyl ether (DME). This behavior is similar as observed before for this catalyst, but with a few differences. ${ }^{10}$ First of all, changes in the activity, such as the initial methanol conversion of $100 \%$ and the fast deactivation appear to occur slower in this setup than in the setup used in our previous work. This is probably caused by the difference in reactor dimensions, as well as by the fact that the gas flows are low compared to the relatively large volume between the outlet of the reactor and the online GC analysis. Because of that, some mixing of the gases occurs, causing changes in activity to appear slower. In addition, the amount of methanol converted per gram of catalyst before deactivation is lower than in our previous work, this is probably caused by differences in reactor size and shape and by the higher concentration of methanol used in this work.

The development of UV-vis bands is very comparable to the development of UV-vis bands that we observed before. ${ }^{10}$ In the beginning of the reaction, $\mathrm{UV}-$ vis absorption bands are observed at 34000 and $26000 \mathrm{~cm}^{-1}$, corresponding to the MTO induction period, where the initial hydrocarbon pool is formed. Subsequently, bands at 30500 and $25000 \mathrm{~cm}^{-1}$ appear, which grow until the catalyst deactivates. The band with the highest intensity, around $25000 \mathrm{~cm}^{-1}$, is caused by charged alkylated benzene and naphthalene species. Also, there is a broad increase in absorbance over the complete range of wavenumbers, due to the formation of extended coke species at the outside of the zeolite crystals. After ca. 30 min time-on-stream, when the catalyst starts to deactivate, the UV-vis spectra remain almost identical with increasing time-on-stream.

The first XRD pattern shown in Figure 2c,d was taken before reaction, while the catalyst was at a temperature of $400{ }^{\circ} \mathrm{C}$ under He flow. Subsequent XRD patterns were recorded during the reaction. The time needed to record an XRD pattern with sufficient quality was ca. $23 \mathrm{~min}$, meaning that the second diffraction pattern was recorded during the first $23 \mathrm{~min}$ of reaction, etc. Because $23 \mathrm{~min}$ is long compared to the time scale of the MTO reaction under these conditions, it means that lowangle peaks of the full XRD patterns are taken at a different moment during the reaction compared to the high-angle peaks in the same pattern. For this reason, the XRD patterns recorded during the reaction were not used in order to determine the zeolite lattice expansion. Instead, the XRD pattern before reaction and the XRD pattern recorded after deactivation of the catalyst were analyzed in order to determine the change in lattice parameters during reaction. All XRD patterns in Figure 2 correspond to the diffraction pattern of chabazite. ${ }^{27}$ Between the first XRD pattern (i.e., before reaction) and the subsequent XRD patterns, some peak shifts toward lower angles are observed, which are best seen in the contour plot in Figure 2c. A peak shift toward lower angles indicates an expansion of the zeolite lattice. In order to quantify this expansion, the XRD patterns before reaction and after deactivation of the catalyst were analyzed using Rietveld refinement. The Rietveld refinement was carried out on XRD patterns before and after reaction for three separate experiments, and the results were averaged. The averaged lattice parameters before and after reaction, as well as the relative expansions of the zeolite framework axes are presented in Table 2. Examples of

Table 2. Zeolite Unit Cell Parameters, Calculated Using Rietveld Refinement of the XRD Patterns before the MTO Process and after Deactivation at a Reaction Temperature of $400{ }^{\circ} \mathrm{C}$ and Corresponding Expansion of the Zeolite Lattice ${ }^{a}$

\begin{tabular}{lccc} 
before reaction & \multicolumn{1}{c}{ CHA } & DDR & LEV \\
$a=b(\AA)$ & $13.54 \pm 0.016$ & $13.81 \pm 0.03$ & $13.04 \pm 0.02$ \\
$c(\AA)$ & $14.75 \pm 0.013$ & $41.32 \pm 0.06$ & $22.66 \pm 0.05$ \\
volume $\left(\AA^{3}\right)$ & $2341 \pm 7$ & $6829 \pm 34$ & $3340 \pm 18$ \\
$R_{\text {exp }}, R_{\text {wp }}$ & $2.87,7.01$ & $3.28,8.83$ & $3.50,6.73$ \\
goodness of fit & 2.44 & 2.70 & 1.92 \\
after reaction & CHA & DDR & LEV \\
$a=b(\AA)$ & $13.56 \pm 0.04$ & $13.88 \pm 0.016$ & $13.04 \pm 0.016$ \\
$c(\AA)$ & $14.88 \pm 0.06$ & $41.43 \pm 0.05$ & $22.779 \pm 0.009$ \\
volume $\left(\AA^{3}\right)$ & $2370 \pm 23$ & $6914 \pm 25$ & $3357 \pm 10$ \\
$R_{\text {exp }}, R_{\text {wp }}$ & $3.17,7.74$ & $3.61,9.54$ & $3.82,6.91$ \\
goodness of fit & 2.44 & 2.64 & 1.81 \\
\multicolumn{1}{c}{ axis } & \multicolumn{4}{c}{0.5} \\
\multicolumn{1}{c}{$a=b$} & $0.2^{b}$ & lattice expansion $(\%)$ & 0.0 \\
$c$ & 0.9 & 0.3 & 0.5
\end{tabular}

$a_{\text {The data }}$ are averaged over three experiments, and the 95\% confidence interval is given. ${ }^{b}$ Expansion not significant, i.e., $t$-test $p$ value $>0.05$.

experimental XRD patterns compared to Rietveld refined data are presented in Figure S1. From this, it is clear that the $c$-axis of the CHA lattice, which is aligned with the long side of the CHA cage, expands $0.9 \%$ during the MTO process. There is also a slight expansion of $0.2 \%$ observed along the $a$ - and $b$ axes, but this expansion is not statistically significant. This means that the CHA cages expand in size during the MTO process, and that hydrocarbons that are formed inside the cages during the MTO process mainly elongate the cage. In previous studies, Wragg et al. observed an expansion of the zeolite cages of SAPO-34 (CHA framework) in the direction of the $c$-axis of ca. $2-3 \%$ during MTO at a reaction temperature of 440-500 ${ }^{\circ} \mathrm{C} .{ }^{13}$ The lower observed lattice expansion in our work is likely caused by the fact that we used the silicoaluminate counterpart of SAPO-34, i.e., SSZ-13 instead of SAPO-34, which was used by Wragg et al. $\mathrm{AlPO}_{4}$-based frameworks, such as $\mathrm{SAPO}-34$, are known to have a more flexible structure than silicoaluminate frameworks. ${ }^{28}$ The possible species that are responsible for the observed expansion are discussed in section 4.1. While these results show the expansion of the zeolite lattice during MTO, it is based only on the XRD patterns before reaction and after deactivation. The time resolution of XRD is not sufficient to watch the zeolite expansion as it proceeds during the reaction, 

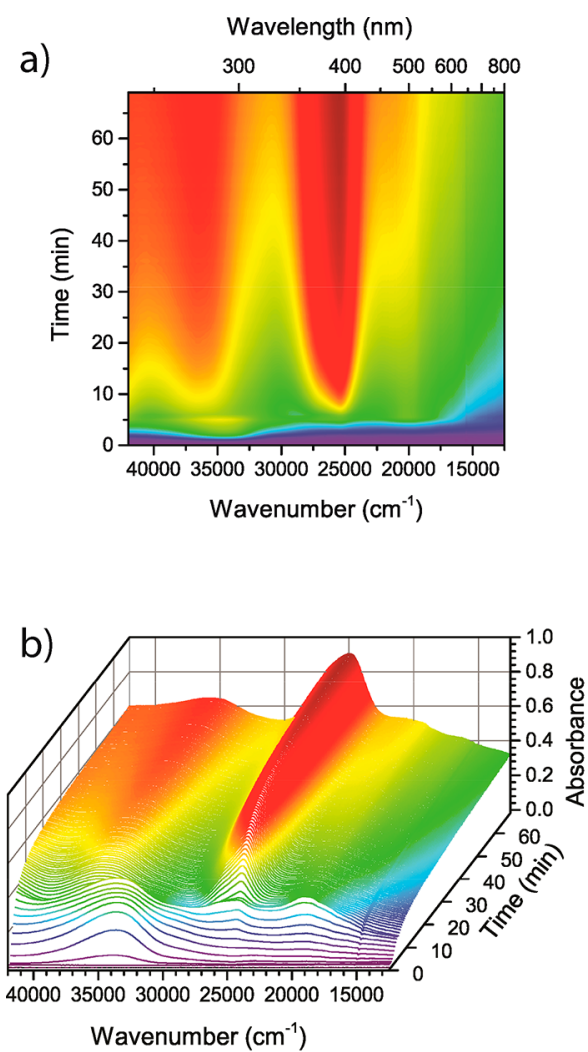

c)
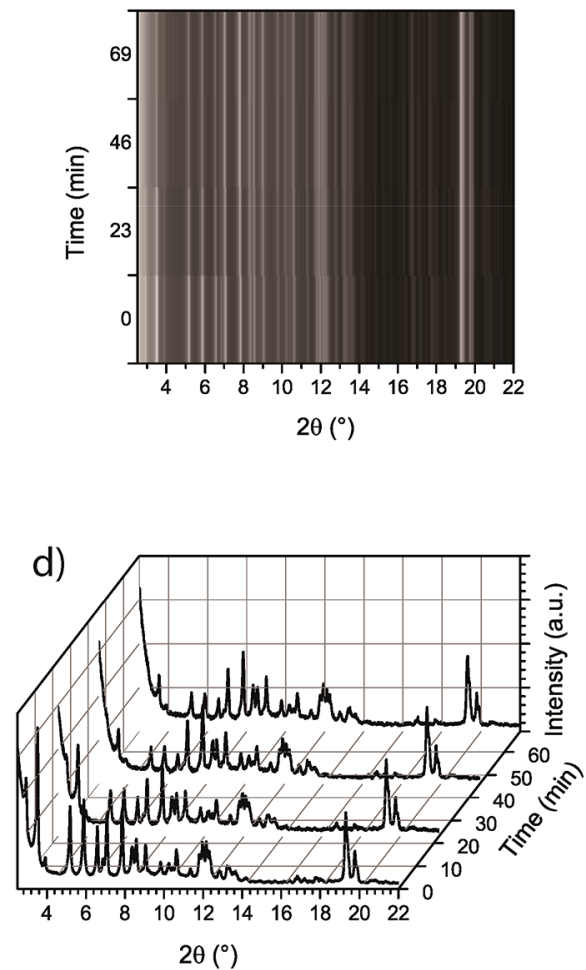

e)

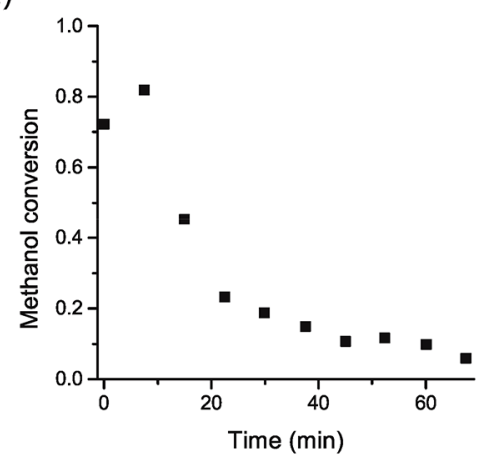

f)

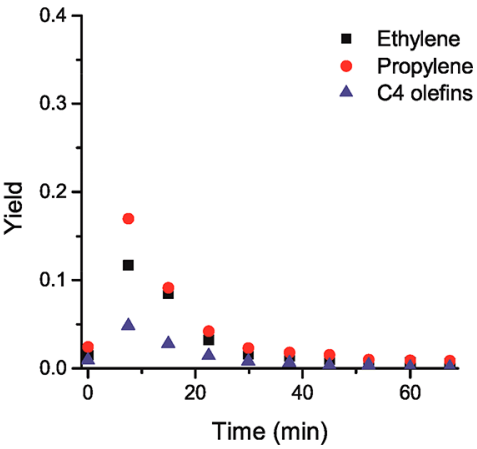

Figure 3. Overview of data obtained from the combined operando XRD and UV-vis setup for the DDR catalyst: (a) contour and (b) waterfall plot of operando UV-vis spectra during the conversion of methanol; (c) contour and (d) waterfall plot of operando X-ray diffraction patterns during the conversion of methanol; (e) methanol conversion and (f) lower olefin yield measured using online GC.

since the majority of the peak shift has already occurred while recording the first XRD pattern during reaction. In order to follow the lattice expansion of the zeolite with increasing timeon-stream, the experiments were also performed, while only measuring the peak shift of one XRD peak in order to increase time resolution. These results are discussed in section 3.3.

For DDR, the UV-vis spectra as well as the XRD patterns and activity data are shown in Figure 3. The activity data and corresponding UV-vis spectra are very similar to those of our previous work. ${ }^{10}$ From the beginning of the reaction, there is high methanol conversion, and during this phase, propylene is the main product, followed by ethylene and butylene. As observed before, deactivation occurs earlier for DDR than for CHA.

In the UV-vis spectra of DDR, an absorption band around $34000 \mathrm{~cm}^{-1}$ is present in the beginning of the reaction. Subsequently, a band around $36000 \mathrm{~cm}^{-1}$ and an intense band around $25000 \mathrm{~cm}^{-1}$ with a sharp shoulder at $24800 \mathrm{~cm}^{-1}$ due to 1-methylnaphthalene are formed. The change in spectral features during the reaction appears more sudden compared to our previous results, because in this setup, spectra are taken from a smaller part of the catalyst bed, so there is less averaging over the catalyst bed. ${ }^{10}$ There is less increase in absorbance over the complete range of wavenumbers compared to CHA, indicating that a less wide variety of hydrocarbon species inside the zeolite cages is formed, as well as less external coke.

The XRD patterns before and during the reaction are shown in Figure 3b,c and correspond to the DDR framework. ${ }^{27}$ The lattice parameters of the XRD patterns before reaction and after deactivation, calculated with Rietveld refinement, and the corresponding lattice expansion are shown in Table 2. Whereas the CHA cage expanded mostly along the $c$-axis, i.e., in the longitudinal direction of the cage, the DDR lattice expands more along the $a$ - and $b$-axes, i.e., in the direction of the width of the cage. The expansion along the $c$-axis of the DDR cage is $0.3 \%$, whereas the expansion along the $a$ - and $b$-axes is $0.5 \%$.

For the LEV catalyst, the operando UV-vis spectra and the operando XRD patterns, as well as the activity data of the MTO process at $400{ }^{\circ} \mathrm{C}$, are shown in Figure 4. A short period of high methanol conversion is observed during which olefins are formed, and the catalyst deactivates after a similar time-onstream compared to DDR, as observed before. ${ }^{10}$ However, due to the sampling interval of the activity data compared to the time before deactivation, the absolute numbers of the activity data for LEV and DDR are not reliable.

The operando UV-vis spectra for LEV are similar to the spectra in our previous work. ${ }^{10}$ The band around $25000 \mathrm{~cm}^{-1}$ is much smaller than for the other two zeolite frameworks, indicating that less aromatics, such as methylated benzene and methylated naphthalene are present inside the small LEV cage during methanol conversion. The XRD patterns shown in Figure $4 \mathrm{c}, \mathrm{d}$ correspond to the LEV topology. ${ }^{27}$

As shown in Table 2, the expansion of the zeolite lattice due to the formation of retained hydrocarbons in the LEV cages is $0.5 \%$ along the $c$-axis, i.e., in the direction of the length of the cage. This means that the LEV cage, similarly to the CHA cage and in contrast to the DDR cage, becomes longer, but not wider during the MTO process.

3.3. Following a Single X-ray Diffraction Peak. Under the conditions described above, i.e., with an XRD recording time of ca. $23 \mathrm{~min}$, the XRD peaks shift so fast that the majority of the peak shift already occurs while recording the first full 

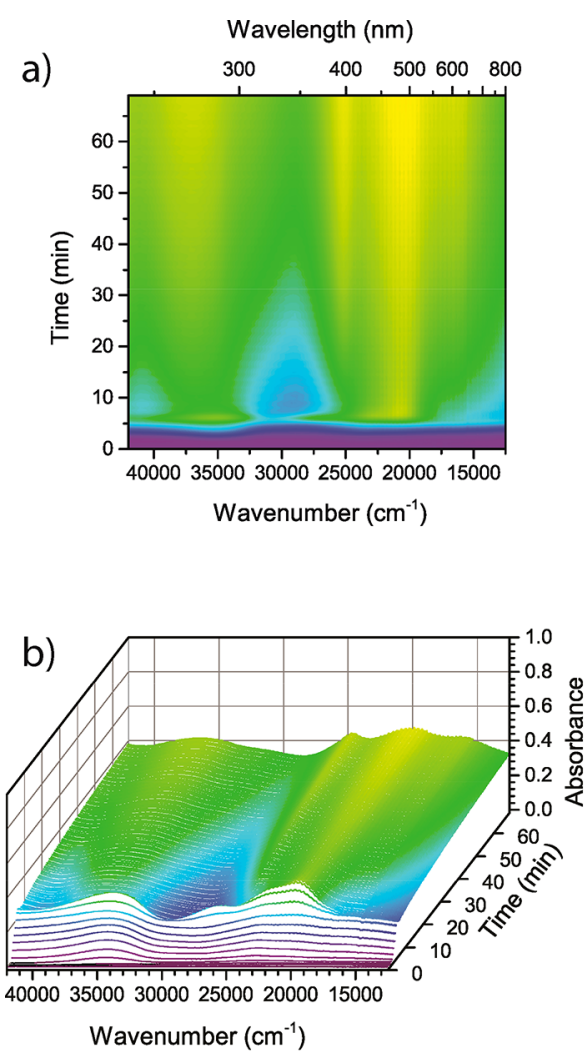

c)
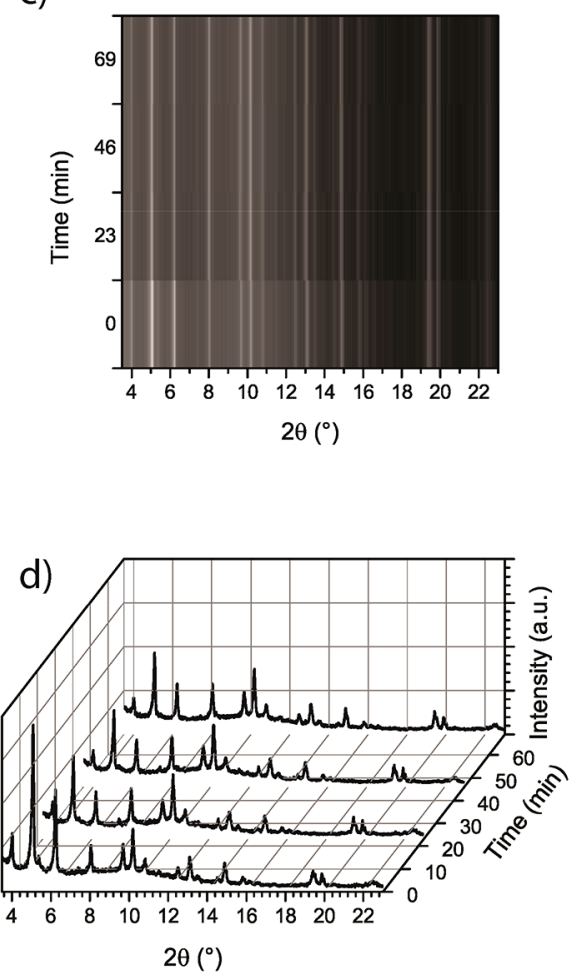

e)

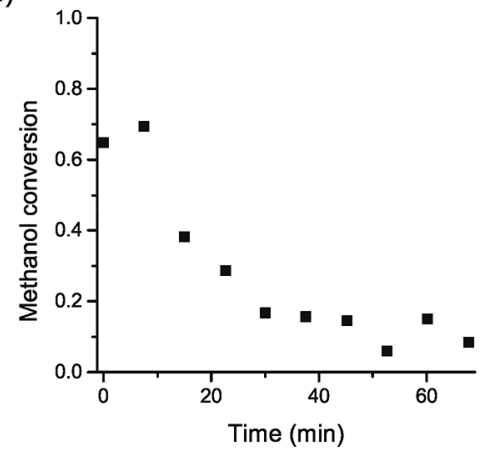

f)

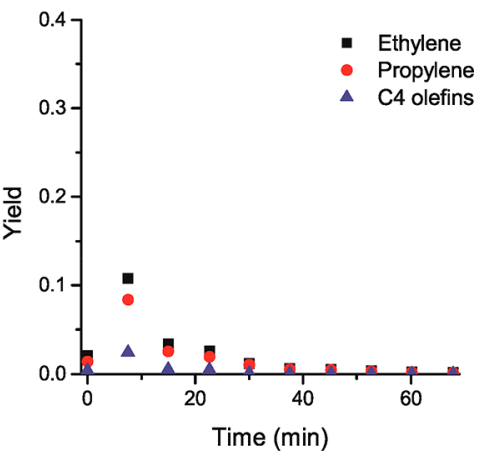

Figure 4. Overview of data obtained from the combined operando XRD and UV-vis setup for the LEV catalyst: (a) contour and (b) waterfall plot of operando UV-vis spectra during the conversion of methanol; (c) contour and (d) waterfall plot of operando X-ray diffraction patterns during the conversion of methanol; (e) methanol conversion and (f) lower olefin yield measured using online GC.

XRD pattern during reaction. While the full powder patterns obtained using this time resolution were used to describe the difference between the zeolite lattice parameters before the MTO process and after deactivation, as described in the previous section, this time resolution was not high enough to follow the changes in XRD peak positions during the MTO reaction. Therefore, the MTO experiments were repeated under the same conditions, but instead of recording the complete XRD pattern, only one XRD peak was recorded. This reduced the measurement time for the XRD data to $5 \mathrm{~min}$, making it possible to follow the shift of a single XRD peak with increasing time-on-stream during the MTO process. The peaks whose shift between the XRD pattern before reaction and after deactivation was most clearly visible were followed; i.e., $11.6^{\circ}$ $2 \theta(h k l=104$, hexagonal setting $)$ for CHA, $9.1^{\circ} 2 \theta(h k l=211)$ for DDR, and $14.9^{\circ} 2 \theta$ (a convolution of $h k l=134$ and $h k l=$ 042) for LEV, and the results are shown in Figure 5.

For CHA, a clear peak shift toward lower diffraction angles during the MTO process is observed, which indicates a lattice expansion. Because the peak also shifts during measurement, the peaks in between the beginning and the end position are broader and have a lower intensity. The lattice expansion, i.e., the peak shift of CHA reaches its maximum after ca. $35 \mathrm{~min}$ time-on-stream, at the same moment that deactivation is observed in the activity data. For DDR, a gradual peak shift toward lower angles is also detected, and similarly to $\mathrm{CHA}$, the maximum lattice expansion is reached at the moment that deactivation is observed, i.e., after 15 min time-on-stream. For $\mathrm{LEV}$, the peak shift occurs less gradual, and the maximum peak shift, i.e., the maximum lattice expansion, is reached after ca. 15 min time-on-stream. This also corresponds to the time until deactivation for the LEV framework.

\section{DISCUSSION}

4.1. Hydrocarbon Species Responsible for Zeolite Lattice Expansion. Using the combination of operando UVvis spectroscopy and operando XRD, we propose plausible species that are responsible for the expansion of the zeolite frameworks. As observed in previous studies, the nature of the retained hydrocarbons depends on the zeolite framework dimensions. ${ }^{10,29-31}$ These differences in nature of the retained species lead to differences between the operando UV-vis spectra of the three different zeolite frameworks. In the CHA framework, which has larger and more symmetric cages than DDR and LEV, a wider variety of hydrocarbon species fit inside the cages, resulting in broader features in the UV-vis spectra. ${ }^{10}$ In Figures 6-8, the operando UV-vis spectra during the MTO process are shown for the three different zeolite frameworks, which show the difference in nature of the hydrocarbon pool species between the three different zeolite frameworks. For each framework, two species are indicated in the figures that build up during the MTO process, and that have dimensions similar to the dimensions of the zeolite cages. These species are plausible candidates to cause the observed zeolite lattice expansion during the MTO process.

For CHA, we showed in our previous work using GC/MS analysis of extracted hydrocarbons that methylated naphthalenes and larger aromatics, such as pyrene, were present inside the zeolite catalyst after the MTO process. ${ }^{10}$ Pyrene was also identified as a species responsible for unit cell expansion in 


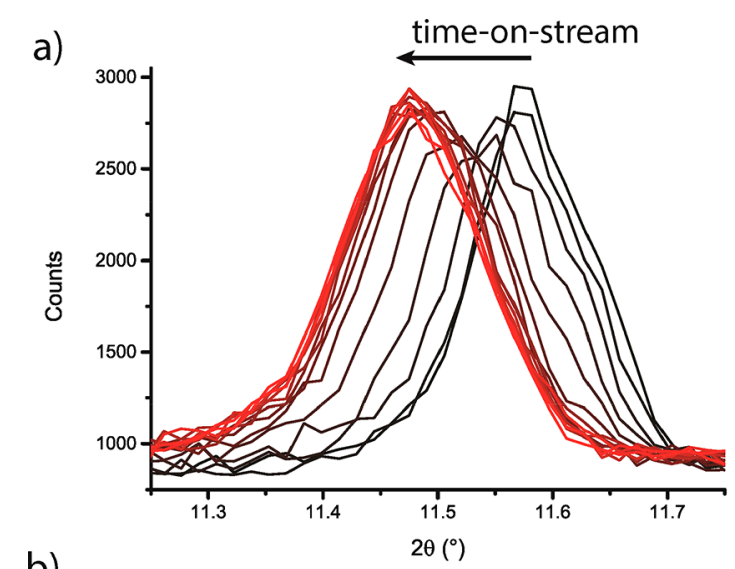

b)

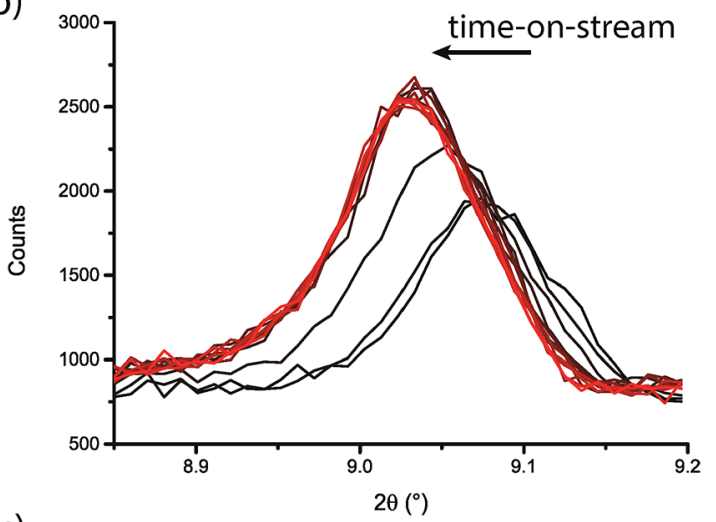

C)

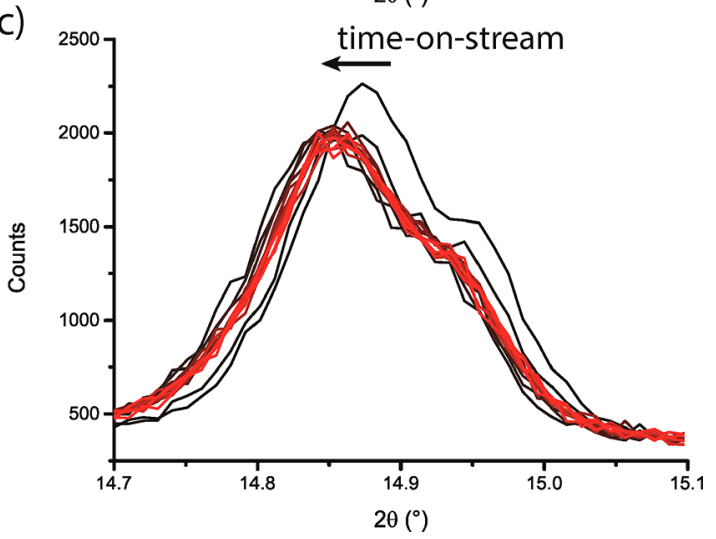

Figure 5. Peak shift of single XRD peaks with increasing time-onstream during the MTO reaction: (a) 104 peak (hexagonal setting) for CHA, (b) 211 peak for DDR, and (c) 132 and 042 peak for the LEV framework.

SAPO-34 by Zokaie et al. ${ }^{16}$ Methylated naphthalenes contribute to the large UV-vis band around $25000 \mathrm{~cm}^{-1}$, whereas larger species, such as pyrene, contribute to the UVvis band around $17000 \mathrm{~cm}^{-1}$. In Figure 6, tetramethylnaphthalene and pyrene are compared to the CHA cage, illustrating that it is plausible that these species cause the unit cell expansion in the direction of the CHA $c$-axis.

For DDR, we concluded before that 1-methylnaphthalene, which causes UV-vis absorbance at $24800 \mathrm{~cm}^{-1}$ is preferentially formed inside the DDR cage. Also, the presence of phenalene, which contributes to the UV-vis absorbance band around $20000 \mathrm{~cm}^{-1}$ is found in DDR after the MTO process. ${ }^{10,32}$ Comparing the size and shape of 1-methylnaphthalene and phenalene to the DDR cage in Figure 7, it is likely that these molecules can cause an expansion more in the width than in the length of the zeolite cage.

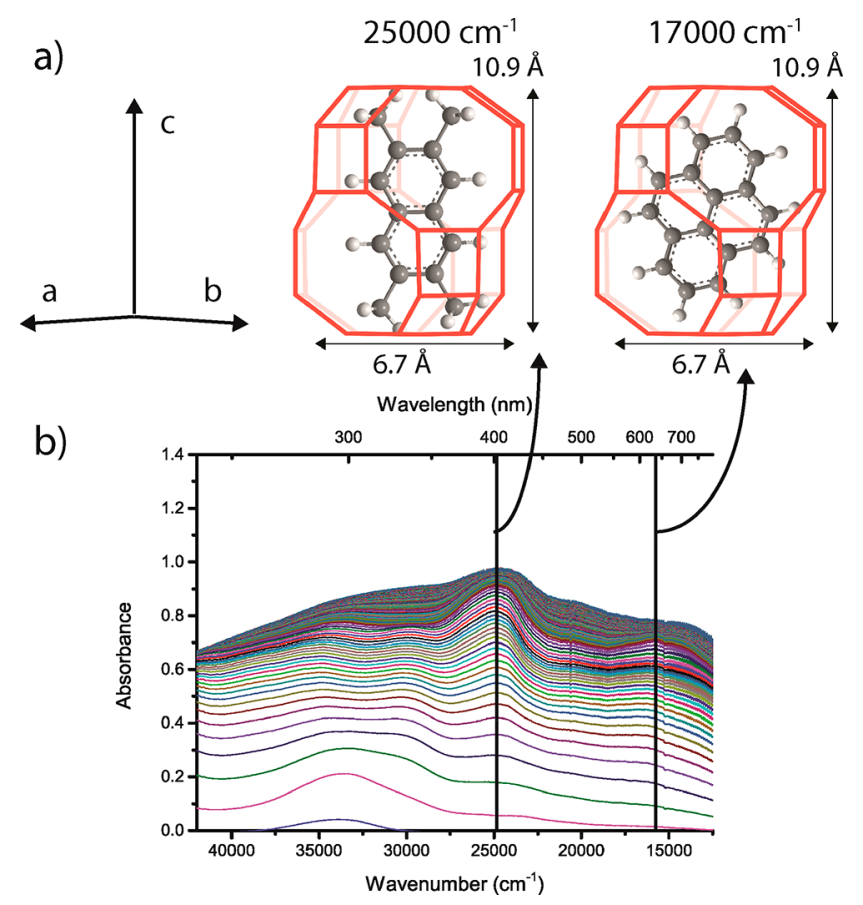

Figure 6. (b) Operando UV-vis spectra during methanol conversion over the CHA catalyst. (a) Hydrocarbon species corresponding to the UV-vis absorbance bands, i.e., tetramethylnaphthalene and pyrene, are compared to the size of the CHA cage. These are plausible hydrocarbon pool molecules causing the lattice expansion observed in XRD.

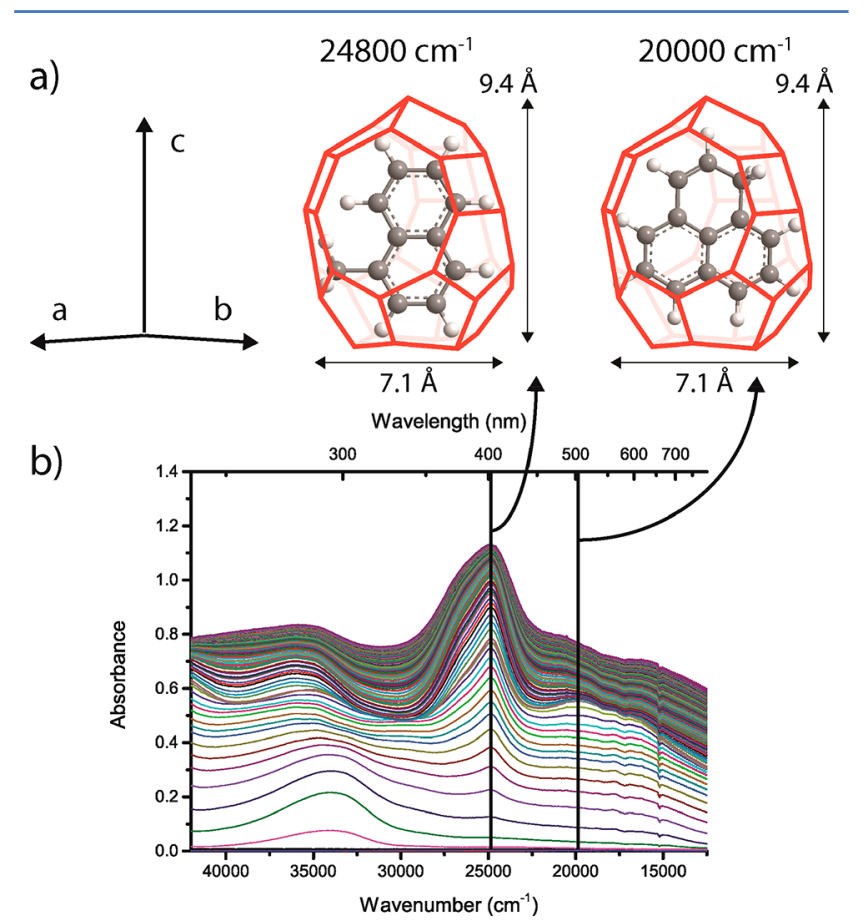

Figure 7. (b) Operando UV-vis spectra during methanol conversion over the DDR catalyst. (a) Hydrocarbon species corresponding to the UV-vis absorbance bands, i.e., 1-methylnaphthalene and phenalene, are compared to the size of the DDR cage. These are plausible hydrocarbon pool molecules causing the lattice expansion observed in XRD.

For LEV, the UV-vis absorbance at $25000 \mathrm{~cm}^{-1}$ is much lower compared to $\mathrm{CHA}$ and DDR. Additionally, in previous 
studies, only small amounts of methylated benzenes and naphthalene were extracted from the deactivated catalyst, but no methylated naphthalenes. ${ }^{10,29}$ Comparing the size of tetramethylbenzene and nonmethylated naphthalene to the LEV cage in Figure 8, it is plausible that these species cause an

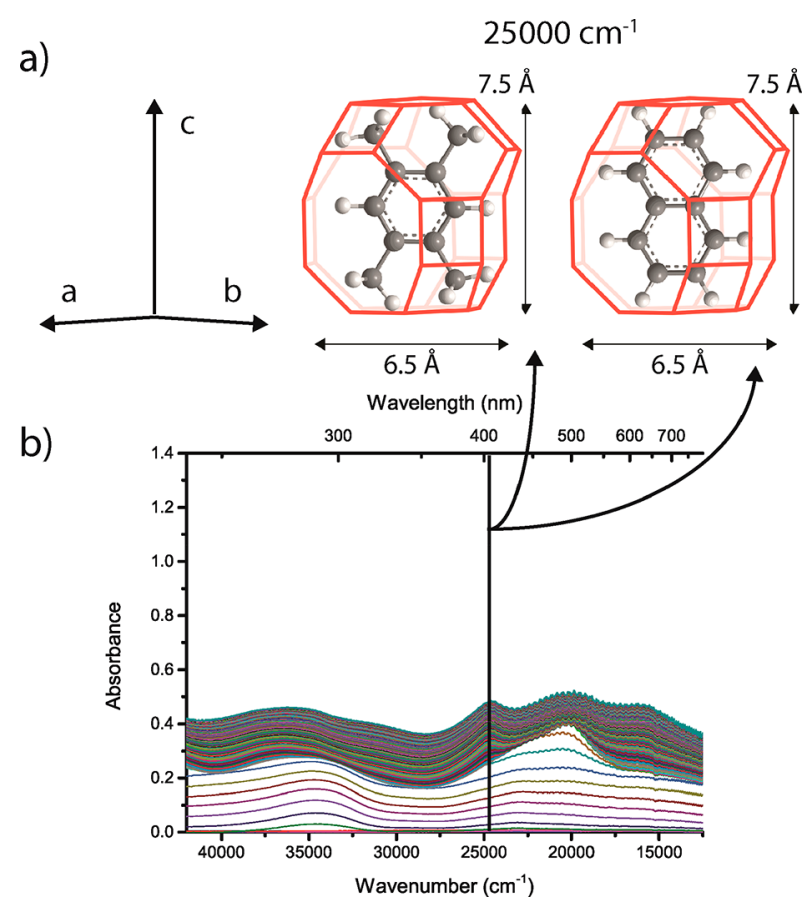

Figure 8. (b) Operando UV-vis spectra during methanol conversion over the LEV catalyst. (a) Hydrocarbon species corresponding to the UV-vis absorbance bands, i.e., tetramethylbenzene and naphthalene, are compared to the size of the LEV cage. These are plausible hydrocarbon pool molecules causing the lattice expansion observed in XRD.

expansion of the zeolite framework mainly in the direction of the height of the cage. In the UV-vis spectra, there is also a clear absorbance band around $20000 \mathrm{~cm}^{-1}$ visible, which is usually assigned to charged aromatic hydrocarbons with more than two rings, such as phenalene in the case of DDR. However, since these species are not found in extracted species after the MTO process, this band is probably caused by larger species outside the zeolite pores in this case.

4.2. Combined XRD Peak Shift and UV-vis Spectroscopy. Two operando methods to follow the evolution of the hydrocarbon pool during the MTO process were combined. Using operando UV-vis spectroscopy, the nature and evolution of retained hydrocarbon species could be followed, while using operando X-ray diffraction, the effect of the formation of these hydrocarbon species on the zeolite lattice was studied. In Figures 9-11, plots are shown for the three different zeolite frameworks, combining MTO activity data with data from operando UV-vis spectroscopy and operando XRD. The methanol conversion on the left $y$-axis shows the active period with a high methanol conversion, followed by deactivation of the catalyst. The first right $y$-axis shows the peak position of the XRD peaks that were discussed in section 3.3. The XRD peak shifts to lower $2 \theta$ values, indicating that the zeolite cages expand. As a measure for the amount of retained hydrocarbons inside the zeolite, the absorbance of the UV-vis bands discussed in the previous section, i.e., the UV-vis

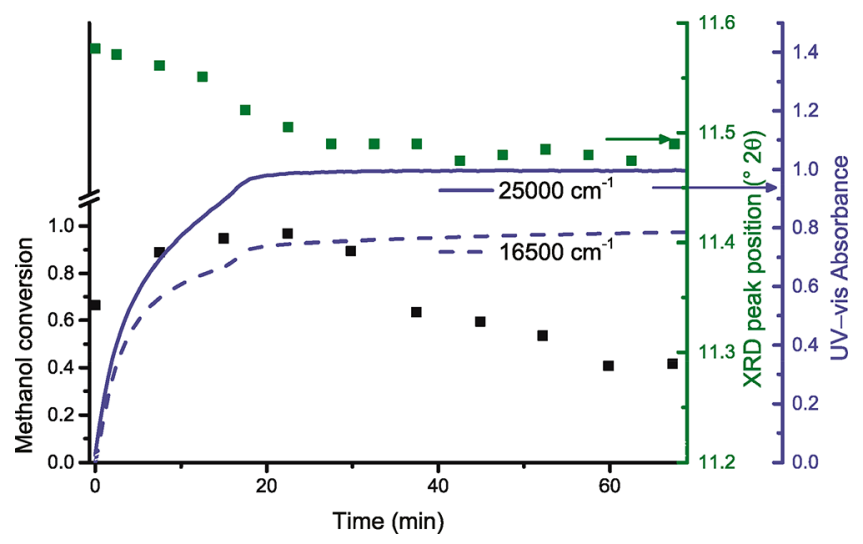

Figure 9. Combination plot for CHA showing the relation between methanol conversion (left $y$-axis), corresponding lattice expansion (XRD peak position, first right $y$-axis), and amount of retained hydrocarbon species (UV-vis absorbance at 25000 and $16500 \mathrm{~cm}^{-1}$, second right $y$-axis).

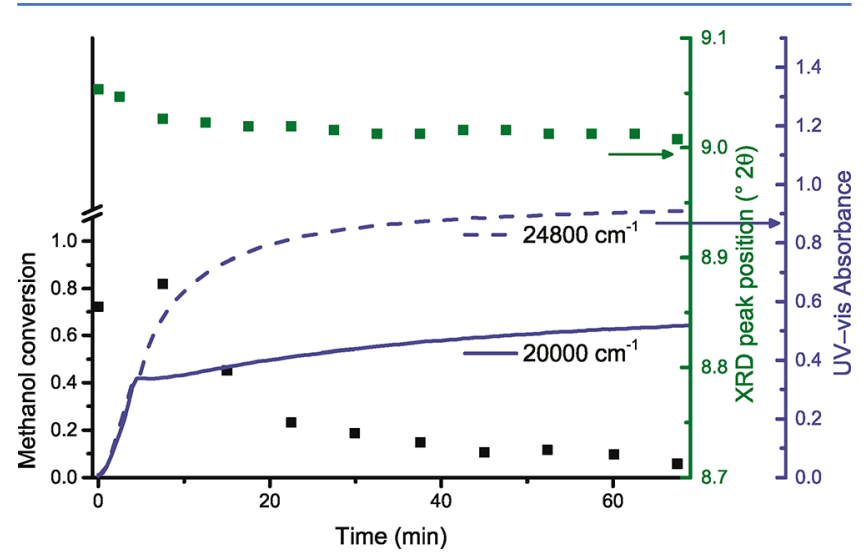

Figure 10. Combination plot for DDR, showing the relation between methanol conversion (left $y$-axis), corresponding lattice expansion (XRD peak position, first right $y$-axis), and amount of retained hydrocarbon species (UV-vis absorbance at 24800 and $20000 \mathrm{~cm}^{-1}$, second right $y$-axis).

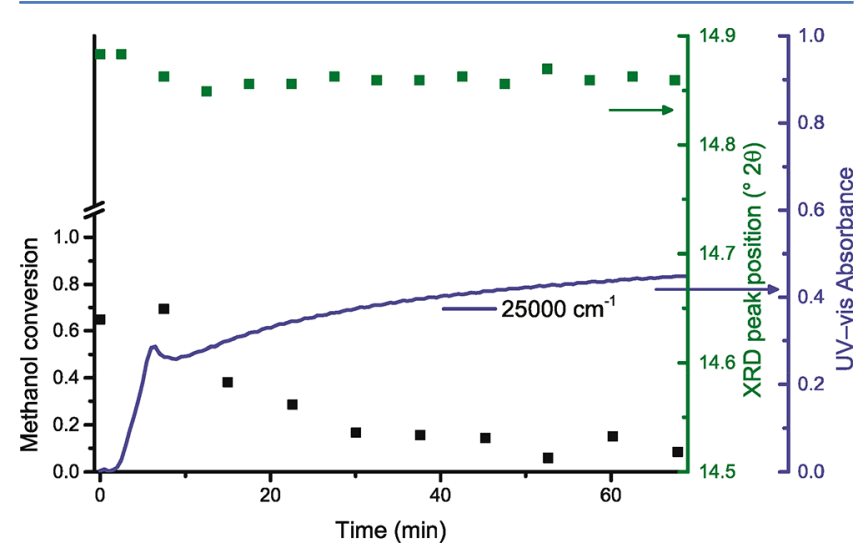

Figure 11. Combination plot for LEV, showing the relation between methanol conversion (left $y$-axis), corresponding lattice expansion (XRD peak position, first right $y$-axis), and amount of retained hydrocarbon species (UV-vis absorbance at $25000 \mathrm{~cm}^{-1}$, second right $y$-axis).

absorbance bands representing species that are possibly responsible for zeolite lattice expansion, are plotted on the second right $y$-axis. During the reaction, the absorbance 
increases, indicating the accumulation of these retained hydrocarbon species in the zeolite catalyst during the MTO process. It was observed before for these small-pore zeolite catalysts, that deactivation of the catalyst is caused by filling of the zeolite pores with hydrocarbons, making it impossible for methanol and products to move through the zeolite crystals. ${ }^{10}$

For CHA, as can be seen in Figure 9, the catalyst is active for ca. $30 \mathrm{~min}$, and during this $30 \mathrm{~min}$, the XRD peak gradually shifts toward lower $2 \theta$ values, indicating an expansion of the zeolite lattice. Once the maximum XRD peak shift is reached, deactivation of the catalyst is observed in the activity data. The XRD peak gradually shifting toward lower angles can indicate that the lattice slowly expands during the MTO process. However, the XRD pattern is an average of the entire reactor bed, so a gradual peak shift can also indicate that the lattice expansion is sudden, but proceeds slowly through the reactor bed. The operando UV-vis spectra are taken from a small spot in the middle of the reactor bed, and the absorbance of the bands around 25000 and $16500 \mathrm{~cm}^{-1}$, which represents the formation of the hydrocarbon pool species that are responsible for lattice expansion, increases for the first $15 \mathrm{~min}$, after which the increase in absorbance becomes slower. This indicates that the formation of carbonaceous deposits slows down after ca. 15 min time-on-stream, which is a sign for deactivation. The fact that deactivation in the middle of the bed is observed around half of the time before deactivation is observed in the activity data, indicates that deactivation by coke formation proceeds through the reactor bed; only once the deactivation has reached the end of the catalyst bed, deactivation is observed in the activity data. This is the typical deactivation behavior during the MTO process in a fixed bed reactor. ${ }^{33-35}$ The combination of activity data with operando UV-vis spectroscopy and operando XRD shows that hydrocarbon formation that results in zeolite lattice expansion proceeds through the reactor bed, causing catalyst deactivation. Once this hydrocarbon formation and lattice expansion have reached the end of the reactor bed, and there is no fresh catalyst left, deactivation is observed in the activity data.

For DDR, a decrease in XRD peak position, i.e., zeolite lattice expansion, is observed during the time that the catalyst is active, as can be seen in Figure 10. Once the maximum XRD peak shift is reached, deactivation of the catalyst is observed after ca. 15 min time-on-stream. Similar to CHA, the UV-vis absorbance of the band around $20000 \mathrm{~cm}^{-1}$, assigned to phenalene, increases until ca. 7 min time-on-stream, around half of the time before deactivation is observed, after which the absorbance stays constant. However, the absorbance at 24800 $\mathrm{cm}^{-1}$, caused by 1-methylnaphthalene, keeps increasing after deactivation of the catalyst. This indicates that in the case of DDR, catalyst deactivation and zeolite lattice expansion are more likely to be caused by phenalene, than by 1methylnaphthalene.

For LEV, similar to DDR, the maximum XRD peak shift toward lower $2 \theta$ values, i.e., the maximum zeolite lattice expansion, occurs after ca. $15 \mathrm{~min}$. At the same time, catalyst deactivation is observed in the activity data. The absorbance of the UV-vis band around $25000 \mathrm{~cm}^{-1}$, which represents hydrocarbon species responsible for zeolite lattice expansion, increases until ca. 7 min time-on-stream. After that, the increase in absorbance becomes much slower, indicating that the middle of the bed, where the UV-vis spectra are recorded, is deactivated.

\section{CONCLUSIONS}

During the Methanol-to-Olefins (MTO) process at a reaction temperature of $400{ }^{\circ} \mathrm{C}$ over zeolite catalysts with CHA, DDR, and LEV topology, the formation and evolution of the retained hydrocarbon species was monitored using operando UV-vis spectroscopy, while zeolite lattice expansion was monitored using operando X-ray diffraction, and activity data were measured using online gas chromatography during the same experiment. All three zeolite frameworks showed lattice expansion during the MTO process because of the accumulation of retained hydrocarbon species inside the zeolite pores. The difference in size and shape of the zeolite cages of the three frameworks results in different retained hydrocarbon species for each zeolite framework. More specifically, the species formed inside the zeolites during MTO that cause zeolite lattice expansion are methylated naphthalene and pyrene in CHA, 1methylnaphthalene and phenalene in DDR and methylated benzene and naphthalene in LEV. The interplay between these specific retained hydrocarbon species and the zeolite framework structures results in a lattice expansion of different magnitude and in different direction for each of the three zeolite frameworks. The largest expansion is observed for CHA, $0.9 \%$ in the direction of the $c$-axis. Furthermore, using this combination of operando UV-vis spectroscopy, operando Xray diffraction and online activity measurements, it was shown that coke formation along the reactor bed, which causes zeolite lattice expansion, causes deactivation of the catalyst. This deactivation starts at the beginning of the reactor and progresses through the catalyst bed. Once this deactivation front reaches the end of the reactor, catalyst deactivation is observed.

\section{ASSOCIATED CONTENT}

\section{Supporting Information}

The Supporting Information is available free of charge on the ACS Publications website at DOI: 10.1021/acscatal.7b04129.

Detailed zeolite synthesis and characterization procedure and experimental $\mathrm{X}$-ray diffraction patterns compared to Rietveld refined data (PDF)

\section{AUTHOR INFORMATION}

\section{Corresponding Author}

*E-mail: b.m.weckhuysen@uu.nl. ORCID ${ }^{\circ}$

Joris Goetze: 0000-0002-4705-7114 Jorge Gascon: 0000-0001-7558-7123

Freek Kapteijn: 0000-0003-0575-7953

Bert M. Weckhuysen: 0000-0001-5245-1426

\section{Author Contributions}

The manuscript was written through contributions of all authors. All authors have given approval to the final version of the manuscript.

\section{Funding}

This research received funding from The Netherlands Organisation for Scientific Research (NWO) in the framework of the TASC Technology Area "Syngas, a Switch to Flexible New Feedstock for the Chemical Industry (TA-Syngas)”.

\section{Notes}

The authors declare no competing financial interest. 


\section{ACKNOWLEDGMENTS}

We thank Marjan Versluijs-Helder and Oscar Kerkenaar (Utrecht University, UU) for technical assistance with the operando XRD setup. Pasi Paalanen and Ramon Oord (UU) are acknowledged for fruitful discussions.

\section{ABBREVIATIONS}

MTO, Methanol-to-Olefins; XRD, X-ray diffraction; GC, gas chromatography

\section{REFERENCES}

(1) Olsbye, U.; Svelle, S.; Bjørgen, M.; Beato, P.; Janssens, T. V. W.; Joensen, F.; Bordiga, S.; Lillerud, K. P. Angew. Chem., Int. Ed. 2012, 51, $5810-5831$.

(2) Olsbye, U.; Svelle, S.; Lillerud, K. P.; Wei, Z. H.; Chen, Y. Y.; Li, J. F.; Wang, J. G.; Fan, W. Chem. Soc. Rev. 2015, 44, 7155-7176.

(3) Haw, J. F.; Song, W.; Marcus, D. M.; Nicholas, J. B. Acc. Chem. Res. 2003, 36, 317-326.

(4) Beato, P.; Schachtl, E.; Barbera, K.; Bonino, F.; Bordiga, S. Catal. Today 2013, 205, 128-133.

(5) Palumbo, L.; Bonino, F.; Beato, P.; Bjørgen, M.; Zecchina, A.; Bordiga, S. J. Phys. Chem. C 2008, 112, 9710-9716.

(6) Qian, Q.; Vogt, C.; Mokhtar, M.; Asiri, A. M.; Al-Thabaiti, S. A.; Basahel, S. N.; Ruiz-Martínez, J.; Weckhuysen, B. M. ChemCatChem 2014, 6, 3396-3408.

(7) Jiang, Y.; Huang, J.; Reddy Marthala, V. R.; Ooi, Y. S.; Weitkamp, J.; Hunger, M. Microporous Mesoporous Mater. 2007, 105, 132-139.

(8) Mores, D.; Stavitski, E.; Kox, M. H. F.; Kornatowski, J.; Olsbye, U.; Weckhuysen, B. M. Chem. - Eur. J. 2008, 14, 11320-11327.

(9) Borodina, E.; Meirer, F.; Lezcano-González, I.; Mokhtar, M.; Asiri, A. M.; Al-Thabaiti, S. A.; Basahel, S. N.; Ruiz-Martínez, J.; Weckhuysen, B. M. ACS Catal. 2015, 5, 992-1003.

(10) Goetze, J.; Meirer, F.; Yarulina, I.; Gascon, J.; Kapteijn, F.; RuizMartínez, J.; Weckhuysen, B. M. ACS Catal. 2017, 7, 4033-4046.

(11) Borodina, E.; Sharbini Harun Kamaluddin, H.; Meirer, F.; Mokhtar, M.; Asiri, A. M.; Al-Thabaiti, S. A.; Basahel, S. N.; RuizMartinez, J.; Weckhuysen, B. M. ACS Catal. 2017, 7, 5268-5281.

(12) De Wispelaere, K.; Wondergem, C. S.; Ensing, B.; Hemelsoet, K.; Meijer, E. J.; Weckhuysen, B. M.; Van Speybroeck, V.; RuizMartínez, J. ACS Catal. 2016, 6, 1991-2002.

(13) Wragg, D. S.; Johnsen, R. E.; Balasundaram, M.; Norby, P.; FjellvÅg, H.; Grønvold, A.; Fuglerud, T.; Hafizovic, J.; Vistad, Ø. B.; Akporiaye, D. J. Catal. 2009, 268, 290-296.

(14) Wragg, D. S.; Akporiaye, D.; FjellvÅg, H. J. Catal. 2011, 279, 397-402.

(15) Wragg, D. S.; O’Brien, M. G.; Bleken, F. L.; Di Michiel, M.; Olsbye, U.; FjellvÅg, H. Angew. Chem., Int. Ed. 2012, 51, 7956-7959.

(16) Zokaie, M.; Wragg, D. S.; Grønvold, A.; Fuglerud, T.; Cavka, J. H.; Lillerud, K. P.; Swang, O. Microporous Mesoporous Mater. 2013, $165,1-5$.

(17) Wragg, D. S.; Grønvold, A.; Voronov, A.; Norby, P.; FjellvÅg, H. Microporous Mesoporous Mater. 2013, 173, 166-174.

(18) Wragg, D. S.; O’Brien, M. G.; Di Michiel, M.; Lønstad-Bleken, F. J. Appl. Crystallogr. 2015, 48, 1719-1728.

(19) del Campo, P.; Slawinski, W. A.; Henry, R.; Erichsen, M. W.; Svelle, S.; Beato, P.; Wragg, D. S.; Olsbye, U. Surf. Sci. 2016, 648, 141149.

(20) Alvarez, A. G.; Viturro, H.; Bonetto, R. D. Mater. Chem. Phys. 1992, 32, 135-140.

(21) Rojo-Gama, D.; Nielsen, M.; Wragg, D. S.; Dyballa, M.; Holzinger, J.; Falsig, H.; Lundegaard, L. F.; Beato, P.; Brogaard, R. Y.; Lillerud, K. P.; Olsbye, U.; Svelle, S. ACS Catal. 2017, 7, 8235-8246.

(22) Stewart, A.; Johnson, D. W.; Shannon, M. D. Stud. Surf. Sci. Catal. 1988, 37, 57-64.

(23) Stewart, A. Zeolite synthesis. EP 0255770 EP 0255 770, 1988.

(24) Zhu, Q.; Kondo, J. N.; Ohnuma, R.; Kubota, Y.; Yamaguchi, M.; Tatsumi, T. Microporous Mesoporous Mater. 2008, 112, 153-161.
(25) Yarulina, I.; Dikhtiarenko, A.; Kapteijn, F.; Gascon, J. Catal. Sci. Technol. 2017, 7, 300-309.

(26) Cats, K. H.; Weckhuysen, B. M. ChemCatChem 2016, 8, 15311542.

(27) Baerlocher, C.; McCusker, L. B. Database of Zeolite Structures http://www.iza-structure.org/databases/ (accessed Jan 23, 2018).

(28) Flanigen, E. M.; Lok, B. M.; Patton, R. L.; Wilson, S. T. Stud. Surf. Sci. Catal. 1986, 28, 103-112.

(29) Bhawe, Y.; Moliner-Marin, M.; Lunn, J. D.; Liu, Y.; Malek, A.; Davis, M. ACS Catal. 2012, 2, 2490-2495.

(30) Deimund, M. A.; Schmidt, J. E.; Davis, M. E. Top. Catal. 2015, $58,416-423$.

(31) Li, J.; Wei, Y.; Chen, J.; Xu, S.; Tian, P.; Yang, X.; Li, B.; Wang, J.; Liu, Z. ACS Catal. 2015, 5, 661-665.

(32) Yarulina, I.; Goetze, J.; Gücüyener, C.; van Thiel, L.; Dikhtiarenko, A.; Ruiz-Martínez, J.; Weckhuysen, B. M.; Gascon, J.; Kapteijn, F. Catal. Sci. Technol. 2016, 6, 2663-2678.

(33) Haw, J. F.; Marcus, D. M. Top. Catal. 2005, 34, 41-48.

(34) Schulz, H. Catal. Today 2010, 154, 183-194.

(35) Yarulina, I.; Kapteijn, F.; Gascon, J. Catal. Sci. Technol. 2016, 6, $5320-5325$. 